\title{
Perception of the Moral Development of the Child With Autoimmune Disease by Clinicians and Researchers
}

\author{
Anderson Díaz-Pérez ${ }^{1,2,4}$, Tahania Chona Rodríguez², Zoraima Romero Oñate ${ }^{2}$, \\ Arley Vega Ochoa ${ }^{2}$, Carmenza Mendoza Cataño ${ }^{3} \&$ Roiman Arenas Potes ${ }^{4}$ \\ ${ }^{1}$ Universidad Simón Bolívar, Departamento de Ciencias Sociales y Humanas, Barranquilla, Colombia \\ ${ }^{2}$ Universidad Popular del Cesar, Facultad Ciencias de la Salud, Valledupar, Colombia \\ ${ }^{3}$ Universidad de la Guajira, Departamento de Ciencias Sociales y Humanas, Riohacha, Colombia \\ ${ }^{4}$ Corporacion Universitaria Rafael Nuñez, Facultad Ciencias de la Salud, Valledupar, Colombia \\ Correspondence: Anderson Díaz-Pérez, Universidad Simón Bolívar, Departamento de Ciencias Sociales y \\ Humanas, Barranquilla, Colombia. Orcid: https://orcid.org/0000-0003-2448-0953. E-mail: \\ ander2711@gmail.com
}

Received: October 28, 2018 Accepted: January 7, 2019 Online Published: January 15, 2019

doi:10.5539/gjhs.v11n2p80 URL: https://doi.org/10.5539/gjhs.v11n2p80

\begin{abstract}
This article presents an analysis about meanings that clinicians and researchers have regarding the autonomy of the mature minor with autoimmune disease, which could lead to different power practices during the moment of taking the informed consent, keeping in mind the doctrine of the minor mature. Consequently, the role of clinicians and researchers in contributing to the moral development or autonomy of the child. The objective was to describe the meanings or perceptions of doctors and researchers, at the time of informed consent, in relation to the autonomy or moral development of the child with autoimmune disease, arising from their experiences, knowledge and prior conceptions of the child. The methodology used was of a qualitative nature with a subjectivist and interpretative approach and a transversal scope. Semi-structured interviews were applied to 21 people, researchers and doctors, who attend children with autoimmune diseases, whose data were analyzed through the Atlas Ti program. 8.0. In conclusion, the informed consent is a process of assertive communication ethical model that seeks the moral structuring of the child beyond what is perceived by the clinician or researcher, in addition the clinicians and researchers consider that to structure the minor is to perceive him as an autonomous subject; which is possible when it shows adherence to treatment and responsible care independently of the tutor's support.
\end{abstract}

Keywords: Mature minor, autoimmune disease, perception, autonomy, informed consent/assent, communication, moral development

\section{Introduction}

The minor who shows maturity to make a decision regarding their participation in an investigation or treatment could mean an ethical problem for researchers and clinicians who are take the informed consent, since it requires a high degree of prudence to not underestimate the autonomy of the minor (Lyon, 1987). They would be forced to check the moral development of the minor from the understanding, scope and meaning of their actions, namely the responsibility of self-care (Oliva, 2014).

Aristotle states that "young people can be geometers and mathematicians and wise in things of that nature, and, on the other hand, they do not seem to be prudent" (as cited in Guillén, 1997, p.6). That ensures that moral virtue, by antonomasia, and prudence are reached late. However, he also affirms that young people, by their ability to be geometers and mathematicians, come to understand situations and be responsible for their own actions (Guillén, 1997, p.6).

Goodwin \& Duke (2011) they point out that, unlike consent, informed consent has a special connotation, since it requires two actors: the minor and the legal guardian; it is not a decision made only by the child. For this reason, it is necessary to clarify the idea of the minor from the mature minor's doctrine, considering his/her right to be informed regardless of age, sociocultural context or legal aspects, in order to achieve an active participation of the minor with a deliberative approach, free of paternalisms, and with a high moral and ethical responsibility to the person who takes informed consent as a process of real communication, independently of the perception of the 
clinician or researcher. Clinicians can perceive that self-care practices are typical of subjects considered mature and autonomous for making decisions, therefore, they could consider the minor as lacking of maturity, leading to power practices in the doctor-patient relationship.

(Sánchez Vazquez, 2007) proposes a classification that can elucidate a little the type of doctor-patient relationships, according to the perspective ethics that have been applied, and that could explain the dynamics of taking informed consent: paternal-moral, normative-legal and differential. Each one of these types of treatment responds to different logics of approaching the ethical problem around the figure of the child: "The first one conceives the infant only as a 'social being', an object of care but not a moral subject; the second introduces the universal dimension made possible by the phenomenon of human rights, the child is already treated as a dignified being, with full rights; the third considers the particular and singular perspective, highlighting the constant alternation of each child between autonomy and subjective vulnerability "(Sánchez Vázquez, 2007, p 179). These types of doctor-patient relationship allow understanding the minor with autoimmune disease according to the perception that clinicians or researchers have in relation to their idea of children or minors as "other moral subjects", as subjects capable of making decisions according to self-regulation and self-care, which is possible through their experience with the disease at an early age, and knowing the type of doctor-patient relationship that weighs in clinical practice and biomedical research.

It is clear that children as a vulnerable population require the representation of parents or guardians, regardless of the perception that the clinician or researcher has about the child's moral development (Serrano López, 2014). This is not at discussion or posed as an ethical problem; the problem lies in the "recognition of the other", that is to say, the recognition of the mature minor as a moral subject that confirms the decision of the tutors, but with awareness of the information received by the clinicians or researchers, under the perception of these last that the minor recognizes his clinical events and understands according to his moral development the message related to the complexity of the autoimmune disease.

Consequently, the general objective was to describe the meanings or perceptions of physicians and researchers, at the time of taking the informed consent, related to the autonomy or moral development of the minor with autoimmune disease, which arise from their experiences, knowledge and previous conceptions about the minor.

\section{Methods}

A qualitative study is proposed whose purpose is to examine human behavior and what governs it, starting from the social fact of a practice that emerges from the meanings and perceptions, as a "historical ontology of ourselves" or a "critique of what we say, we think and we do ", in order to create new ways of being and understanding others in their practices, but in the dynamics of changing who we are (Monatschrift, 1984, Packer, 2013).

In relation to the epistemological perspective, subjectivism will be considered as a position to recognize, understand and interpret the meanings and the symbolic understood by the individual subject, and to be able to generalize to the collective in particularities, in order to understand the particular reality of each individual, from the particular subject point of view [clinical or investigator], since, according to the perception of the minor, there will be judgments related to autonomy, freedom and responsibility. The purpose is to delimit the validity of the truth to the subject that understands, knows and manifests it in a practical (Packer, 2013, pp. 7-8).

The population consisted of clinicians and researchers who have direct contact with children diagnosed with some type of autoimmune disease. 30 interviews were performed, of which 27 met the clear criteria when answering the questions. The main criterion for inclusion was that the specialists and subspecialists work in the city of Barranquilla and that they have the wish to participate in the research. As a data collection technique, a semistructured [focused] interview was designed, which allowed to analyze and examine the meanings of autonomy, of researchers and clinicians through subjective experiences with objective analysis to recognize how the power practices of the doctor-patient relationship type were constituted.

A descriptive statistical analysis was carried out with the SPSS $21{ }^{\circledR}$ program of the most important characteristics of the population, including the age of the persons, years of experience, sex, specialty, and direction of projects whose subject of research are children. Frequency and percentage calculations were applied, which are presented in frequency tables.

The analysis of the qualitative information was carried out through interview recordings and their subsequent transcription using the Dragon Notes ${ }^{\circledR}$ program, or through direct analysis using the Atlas Ti $8.0 ®$ program. Systematization and information processing. The analysis was carried out through a subjectivist-interpretive approach, where the following stages were established: 1 . We proceeded to the transcription of the 21 interviews made to pediatric clinicians and researchers, pediatric pulmonologists, rheumatologists and immunologists who 
have had experience at the management of children and adolescents with autoimmune disease. 2 . The identification of categories, subcategories and emerging categories was carried out using the Atlas Ti 8.0® program. 3. A report was prepared with all the interventions or responses of the informants, taking into account all the categories, subcategories and emerging categories found and related with their different annotations, for a total of 66 categories divided between subcategories and emerging categories with 292 annotations (Bardin, 1991, pp. 38-44).

The ethical component of the study was approved by the ethics committee of the Doctorate program of the Universidad del Bosque, classifying the study as risk-free according to the resolution 0008430/93. The principle of confidentiality was safeguarded by applying informed consent to clinicians or researchers.

\section{Results}

Table 1 shows that $61.9 \%$ of the clinicians interviewed were between the ages of 21 and 30 ; in a smaller proportion, the clinicians are between 50 and 59 years old. The $9.5 \%$ are between the ages of 60 and 69 . The $66.7 \%$ of the clinicians are female pediatricians and $14.3 \%$ are male pediatricians. A gynecologist who was interview mentions having experience with girls with autoimmune disease, representing $4.8 \%$. In the same percentage a pediatrician and an infectologist, representing 9.6\%, who also mention having experience in research with children. Representing $4.8 \%$, there is a rheumatologist and immunologist who also describes having enough experience in treating children with autoimmune disease and who is also a recognized researcher in the area. The $9.5 \%$ of the interviewees demonstrated to have significant experience in relation to the development of research in children and adolescents and the $90.5 \%$ describe that they have dedicated themselves to clinical care.

Table 1. Characteristics of the clinicians and researchers interviewed

\begin{tabular}{|c|c|c|c|c|c|c|c|c|c|c|c|}
\hline \multicolumn{2}{|c|}{$\begin{array}{l}\text { Age range of } \\
\text { specialists }(\%))\end{array}$} & \multirow{2}{*}{ Gender } & \multicolumn{5}{|c|}{ Medical speciality } & \multirow{4}{*}{$\begin{array}{l}\text { Researcher or } \\
\text { Clinician }\end{array}$} & $\begin{array}{l}\text { Directs } \\
\text { projects } \\
\text { children }\end{array}$ & $\begin{array}{r}\text { research } \\
\text { in }\end{array}$ & \multirow{2}{*}{ Total } \\
\hline 21-30 & $\begin{array}{l}13 \\
(61,9)\end{array}$ & & $\begin{array}{l}\text { Gynecology } \\
\text { n (\%) }\end{array}$ & $\begin{array}{l}\text { Pediatrícs } \\
\text { n (\%) }\end{array}$ & $\begin{array}{l}\text { Pediatrics } \\
\text { and } \\
\text { infectology } \\
\text { n (\%) }\end{array}$ & $\begin{array}{l}\text { Rheumatology and } \\
\text { immunologyn (\%) }\end{array}$ & $\begin{array}{l}\text { Total } \\
\text { n (\%) }\end{array}$ & & $\begin{array}{l}\text { No } \\
\text { n (\%) }\end{array}$ & $\begin{array}{l}\text { Yes } \\
\text { n (\%) }\end{array}$ & \\
\hline $31-40$ & $5(23,8)$ & Female & $1(4,8)$ & $14(66,7)$ & $0(0,00)$ & $0(\mathbf{0 , 0 0})$ & $\begin{array}{l}15 \\
(71,4)\end{array}$ & & $\begin{array}{l}19 \\
(90,5)\end{array}$ & $\mathbf{0}(\mathbf{0 , 0 0 )}$ & $\begin{array}{l}19 \\
(90,5)\end{array}$ \\
\hline $50-59$ & $1(4,8)$ & Male & $0(0,00)$ & $3(14,3)$ & $2(9,6)$ & $1(4,8)$ & $\begin{array}{l}6 \\
(28,6)\end{array}$ & & $0(0,00)$ & $2(9,5)$ & $2(9,5)$ \\
\hline $60-69$ & $2(9,5)$ & Total & $1(4,8)$ & $17(81)$ & $2(9,6)$ & $1(4,8)$ & $\begin{array}{l}21 \\
(100)\end{array}$ & Total & $\begin{array}{l}19 \\
(90,5)\end{array}$ & $2(9,5)$ & $\begin{array}{l}21 \\
(100)\end{array}$ \\
\hline Total & $\begin{array}{l}21 \\
(100)\end{array}$ & Source: & epared by th & author. $n$ & umber of pec & interviewed; (\%): pe & centage & & & & \\
\hline
\end{tabular}

\subsection{Autonomy Perceived by Clinicians and Researchers in the Mature Minor With Autoimmune Disease}

The analysis of categories, subcategories and emerging categories related to the meanings and practices of clinicians and researchers with respect to the autonomy of the minor during the process of informed consent. The categories of analysis were defined taking in mind the impression of the meaning of the relationship between meanings and practices with the perception that clinicians and researchers have of the autonomy and moral development of the minor with some type of autoimmune disease at the moment of demonstrating their ability to make decisions regarding their health.

In the autonomy category, the comments made by the respondents in relation to how they perceive the autonomy of the minor with autoimmune disease were groupe. 
According to clinicians and researchers, the minor's autonomy, which depends to a large extent on his or her understanding of the disease and recognition of his or her duty, is reflected in his self-care practices, but also in the way he interacts with the environment and in the independence it has from its parents, understanding that its autonomy is closely related to his ability to listen rather than his age, which raises the idea that experience with the disease gives the minor the ability to understand the consequences and, therefore, structure in a better way his right to decide.

The voices presented below describe the dynamics perceived by the clinicians in relation to the autonomy of the minor with autoimmunity:

Question: In your experience, at what point can the minor be considered a mature subject?

- [E-1]-[1:89]: An autonomous minor, with recognition of his duty, since his disagreement denotes a lack of maturity.

- [E-2]- [1:232]: When is able to make moral judgments coherent to his health.

- [E-12]-[1:242]: As long as is able to make rational decisions and keep in mind their consequences.

In this order of ideas, the autonomy of the minor is reflected in elements like cognitive abilities, such as the understanding of the illness, emotional and mental aspects that are reflected in self-care practices, and, therefore, in the improvement of their quality of life. . However, clinicians believe that this could be linked to their moral maturity and possibly to the age of the minor with autoimmunity.

The following subcategories emerge to support the perception that clinicians have about categories such as the minor's autonomy and moral maturity. These arise from conceptual principles represented in the voices of the respondents.

\subsection{Subcategory: Understanding the Disease}

This subcategory is related to the way in which the minor understands the risks of the disease and the benefits of the treatment in relation to the improvement of his quality of life.

Question: Do you consider that the experience of minor patients with some type of autoimmune disease contributes or not to the development of moral judgments?

- [E-3]-[1:153]: It depends on the age of the patient, his degree of maturity, the type of disease, but above all how informed is he about his condition.

Question: What elements do you consider important at the time to consider that the minor can or can not make a decision regarding a new treatment?

- $\quad$ [E-2]-[1:93]: That he understands his disease in relation to the complications and its repercussion to his quality of life, but above all that he understands that he can die at an early age.

Question: Based on your experience, what it would depend on the minor can make an important decision regarding their health, specifically their self-care?

- [E-1]-[1:131]: Of his age, of the knowledge he has about his illness, of the security that his environment provides him and of the experience he has had with the disease.

Subcategory: Recognition of duty by professionals in clinical practices (care and research) during the taking of informed consent to the child with autoimmunity.

This subcategory is linked to the analysis that the child should make about their desire to improve their quality of life with the support of health professionals and also of their family, the wishes of their age are related to their moral judgments of self-care, as expressed in the following voices:

Question: Which elements do you think are important to consider that the minor can or can not make a decision regarding the new treatment?

- [E-1]- [1:89]: An autonomous minor, who has recognition of his duty.

\subsection{Subcategory: Responsibility}

A minor is considered responsible when is able not only to make decisions, but also to take responsibility for his own health.

Question: In your experience, at what time can the minor be considered a mature subject?

- [E-15]- [1:245]: At the moment in which the minor understands his condition and takes medication in a 
timely manner as prescribed by the doctor.

\subsection{Subcategory: Will and Self-Care Habits}

Clinicians believe that the minor's relationship with their parents has a great influence on how the minor accepts and contributes to their care. These elements of contribution are reflected in self-care a practice, which is extrapolated to other personal and environmental dimensions. Clinicians also mention that the will of the minor in relation to their self-care habits depends on the severity or stage in which the illness is found, since it can be confronted with pain and anguish. However, in the information provided by clinicians, these physical and psychological elements are not an impediment, since their adherence to treatment depends more on the minor's defined conscience and the positive sense they give to their life.

Question: What elements do you consider important at the time to consider that the minor can or can not make a decision regarding a new treatment?

- [E-11]-[1:106]: The voluntariness of the minor for the treatment and the opinion that the parents have regarding the degree of autonomy of the minor.

Question: Doctor, from your perception, the maturity that is possibly demonstrated by the minor in matters of self-care could be extrapolated to other areas of his life and in what sense?

- [E-10]- [1:176]: Yes, of course, because what you learned in your self-care is extrapolated to your personal development, to develop in your daily life to relate to other individuals.

Question: Doctor, from your perception, the maturity that is possibly demonstrated by the minor in matters of self-care could be extrapolated to other areas of his life and in what sense?

- [E-2]-[1:168]: Yes, as long as he demonstrates that he has conscience defined or addressed in both physical and psychological care.

\subsection{Subcategory: Experience With the Disease}

The clinicians consider that the experience with the disease contributes greatly to the development of the autonomy of the minors, because it creates in them common sense in relation to the degree of understanding that they have of the disease, their capacity of discernment in adverse situations with respect to their health, but also in the social aspect, since they are able to determine the consequences of their actions and the impact they have on their daily experiences.

Question: Do you consider that the experience of minor patients with some type of autoimmune disease contributes or not to the development of moral judgments?

- [E-13]-[1:162]: Yes, since he is continually involved in realities that require him to apply ethical principles and values such as autonomy, taking in mind that he is a minor.

Question: Describe how you would inform the minor about the new treatment and what does the level of information that is provided depend on?

- [E-20]-[1:37]: The minor often does not have the ability to discern clearly. But the minor with this type of connective tissue diseases, are children who develop much "common sense", the minor must be made to understand the importance of medicines; The problem lies mainly in the route of administration "injections" and with the periodicity with which are administrated especially that this type of pathology are carried out biological therapies. Most minors when they are explained well end up accepting the treatment for at least one injection per week.

Question: Doctor, from your perception, the maturity that is possibly demonstrated by the minor in matters of self-care could be extrapolated to other areas of his life and in what sense?

- [E-10]-[1:176]: Yes, of course, because what he learned in his self-care is extrapolated to his personal development, to develop in his daily life to relate to other individuals.

Question: According to your experience, what would depend on the minor being able to make an important decision regarding his health, specifically his self-care?

- [E-15]- [1:144]: Depends of the degree of knowledge he has about his pathology. Be aware of the disease he has and the consequences of poor self-care.

Question: What elements do you consider important at the time to consider that the minor can or can not make a decision regarding a new treatment? 
- [E-6]-[1:98]: You should consider the mental state, that it is a person with sufficient conditions. With adequate autonomy to make a decision about your future.

Question: In your experience, at what time can the minor be considered a mature subject?

- [E-12]-[1:242]: As long as he is able to make rational decisions and keep in mind the consequences of them.

\subsection{Subcategory: Active Subject}

Clinicians consider that the active subject or, better, the minor mature is the one who recognized himself by his experience with the disease, but also by his degree of understanding of the pathology, as mentioned above. However, these elements are determined by their independence or dependence on their parents, their ability to listen, which is related to their health status, and self-care practices, as stated in the following voices:

Question: In your experience, at what time can the minor be considered a mature subject?

- [E-13]- [1:244]: It is independent of age at the moment in which a patient with a pathology is aware of their pathology and is responsible for their self-care.

- [E-17]-[1:247]: It depends on the patient's condition and their socio-cultural factors.

Question: Doctor, from your perception, the maturity that is possibly demonstrated by the minor in matters of self-care could be extrapolated to other areas of his life and in what sense?

- [E-16]- [1:182]: No, it must always be the father or mother who endorses the treatment and conduct.

- [E-21]-[1:286]: It depends on the degree of dependence that the minor has with his mother, since overprotection is a barrier [...]

Question: Do you consider that the experience of minor patients with some type of autoimmune disease contributes or not to the development of moral judgments?

- [E-4]- [1:154]: It would depend on the means he uses to make himself understood.

Question: What elements do you consider important at the time to consider that the minor can or can not make a decision regarding a new treatment?

- [E-14]-[1:111]: If is able to explain the benefits of the treatment or the medication.

- $\quad$ [E-15]-[1:112]: According to the quality and clarity with which the minor exposes the information.

Question: Based on your experience, what it would depend on the minor can make an important decision regarding their health, specifically their self-care?

[E-6]- [1:131]: Of his age, of the knowledge he has about his illness, of the security that his environment provides him and of the experience he has had with the disease.

\subsection{Development or Moral Maturity Perceived by Clinicians and Researchers in the Mature Minor With} Autoimmune Disease

In the category of development or moral maturity the comments of the clinicians are described in relation to the determining elements that influence the moral development of the minor with a diagnosis of autoimmune disease, for example, related to physical and psychological limitations [mental capacity] appropriate to the minor's age or the severity of the disease. In addition, social and family aspects are taken into account, such as cultural aspects of parenting and dependence on parents. Finally, we consider the role of clinicians in the construction of moral elements, such as autonomy, which are reflected in self-care practices from the training process performed by the clinician to the child with autoimmune disease

Clinicians believe that the minor's moral maturity can be judged by the degree of self-understanding of everything related to self-care as their main duty, which depends on their understanding of the information provided by the clinician. On one hand, the submission of the minor to the treatment is crucial, since the clinicians consider, from the principle of beneficence, that the minor does not have enough capacity of understanding to participate in the decision on the treatment to be followed. On the other hand, some clinicians have the intention of contributing to the moral development of the minor by training the minor's in relation to their self-care, which is related to the type of doctor-patient relationship, expressed in the clear explanation of the benefits and risks adjusted to the cognitive level of the minor, appropriate to their age and their experience with the disease, in order to achieve recognition of their duty and, therefore, their ability to decide [autonomy]. Below are the voices that describe these elements: 
Question: From your assistance or research practice, how do you think it contributes to the strengthening of moral development, understood as the autonomy, freedom and responsibility of the minor for making decision making through moral judgments?

- $\quad$ [E-21]-[1:224]: It depends on the family nucleus, it is not the same when the tutor is a single mother, since they tend to be overprotective, and the degree of dependency increases. It clarifies that the role of parents is to make minors more and more independent. If it is an investigation, first talk with the parents to explain the treatment and reinforce the idea with the minor, "worth it", and then the minor, since the parents can say no, then it would not be prudent to expose the child. I contribute from the clinic in "making it feel important", a treatment with affection and respectful, "open". To lower it to the level of the language and above all a "culture of reaching the child", this also depends on the degree of education of the parents. Without lying in anything.

- [E-20]-[1:221]: Explaining the benefits and complications of the treatment. Teach the child about the effects of the disease and that it may even die. Increasing the degree of awareness in the child with respect to the disease.

Question: In your experience, at what time can the minor be considered a mature subject?

- [E-21]-[1:251]: If it is independent and if it is a minor that follows rules, understanding that has more to do with education than with age. Bearing in mind that each age manifests things differently, which does not mean a lack of understanding, but the language must be adjusted.

\subsection{Subcategory: Mental Capacity}

Clinicians or researchers evaluate the mental capacity of the minor, keeping in mind the chronicity of the illness, the way the minor interacts with the environment and how the disease influences their daily activities. As a result of this evaluation, the clinician may consider referring the minor to the psychologist for the management of anxiety and fear as a way to strengthen their participation in the understanding of the diagnosis, but above all to strengthen their self-care with the support of their family, since the psychological support is also directed to the family nucleus. These elements are expressed in the following voices:

Question: From your assistance or research practice, how do you think it contributes to the strengthening of moral development, understood as the autonomy, freedom and responsibility of the minor for making decision making through moral judgments?

\section{- [E-13]-[1:215]: Providing psychological support.}

Question: ¿Based on your experience, what it would depend on the minor can make an important decision regarding their health, specifically their self-care?

- $\quad$ [E-2]-[1:126]: To the support that their family can provide them and a good psychological support.

- [E-11]-[1:139]: It depends on how you handle pain and anguish, which could prevent you from contributing in a good way to self-care habits.

\subsection{Subcategory: Social and Family Aspects}

Clinicians consider that one of the most important elements that contribute to the understanding of the minor are the cultural aspects and the degree of dependency of the child with the parents. Therefore, clinicians believe that the way to contribute to the moral development of the minor is through informed consent, as it is an opportunity they have to explain to the minor the advantages of self-care, with a language appropriate to their degree of moral development and above all, without lying, because minors can perceive the lies regardless of their age. Clinicians believe that the degree of moral development of the minor may also depend on the type of disease, but especially on their experience with the disease and how the minor faces it. The clinician can contribute helping him to be more responsible, with projection to several dimensions of his life, as well as to improve the interaction with the environment, regardless of his age, where the family contributes in an important way. Here are the voices:

Question: From your assistance or research practice, how do you think it contributes to the strengthening of moral development, understood as the autonomy, freedom and responsibility of the minor for making decision making through moral judgments?

- $\quad$ [E-21]-[1:223]: It depends on the family nucleus, it is not the same when the tutor is a single mother, since they tend to be overprotective, and the degree of dependency increases. It clarifies that the role of parents is to make minors more and more independent. If it is an investigation, first talk with the parents to explain the treatment and reinforce the idea with the minor, "worth it", and then the minor, since the 
parents can say no, then it would not be prudent to expose the child. I contribute from the clinic in "making it feel important", a treatment with affection and respectful, "open". To lower it to the level of the language and above all a "culture of reaching the child", this also depends on the degree of education of the parents. Without lying in anything.

Question: In your experience, at what time can the minor be considered a mature subject?

- [E-17]-[1:247]: It depends on the patient's condition and their socio-cultural factors.

Question: According to your experience, what would depend on the minor being able to make an important decision regarding his health, specifically his self-care?

- [E-3]-[1:127]: It would depend on their degree of maturity, that they understand and accept their illness, that they carry out all the activities necessary for their management with family support.

- [E-6]-[1:131]: Of his age, of the knowledge he has about his illness, of the security that his environment provides him and of the experience he has had with the disease.

Question: Doctor, from your perception, the maturity that is possibly demonstrated by the minor in matters of self-care could be extrapolated to other areas of his life and in what sense?

- [E-3]-[1:169]: I consider that the minor who is responsible for self-care, most likely is also responsible for other aspects: school, family life, social environment.

Question: What elements do you consider important at the time to consider that the minor can or can not make a decision regarding a new treatment?

- $\quad$ [E-20]-[1:20]: It depends on the type of autoimmune pathology and there are many that can be improved. Explain to the minor the treatment and control of the disease. I believe that children after 8 to 9 years old can understand.

Question: Doctor, from your perception, the maturity that is possibly demonstrated by the minor in matters of self-care could be extrapolated to other areas of his life and in what sense?

- $\quad$ [E-18]-[1:84]: Yes, since the positive sense that gives it to his self-care is projected to other areas or dimensions of his life.

\subsection{Subcategory: Differentiated Process of Objectification [Schooling]}

The meanings that clinicians have regarding the autonomy and moral development of the minor are expressed in practices that end in submission or contribute directly to the moral development of the minor, as an ethical practice on the part of the clinician that could be called the process of [objectification] differentiated schooling, from a dynamic range proposed from the minor's own potentiating elements perceived by the clinicians, those represented the minor objectively, and those related to the sociocultural context in which he coexists with the disease; These elements are the one that could determine the type of communication strategy and how to morally structure the child / either the submission strategy (subjection) or, as comprehension strategies, to contribute to the minor's development as an active subject. It is a way to structure the minor to improve their self-care and, therefore, their quality of life (see Figure 1). 


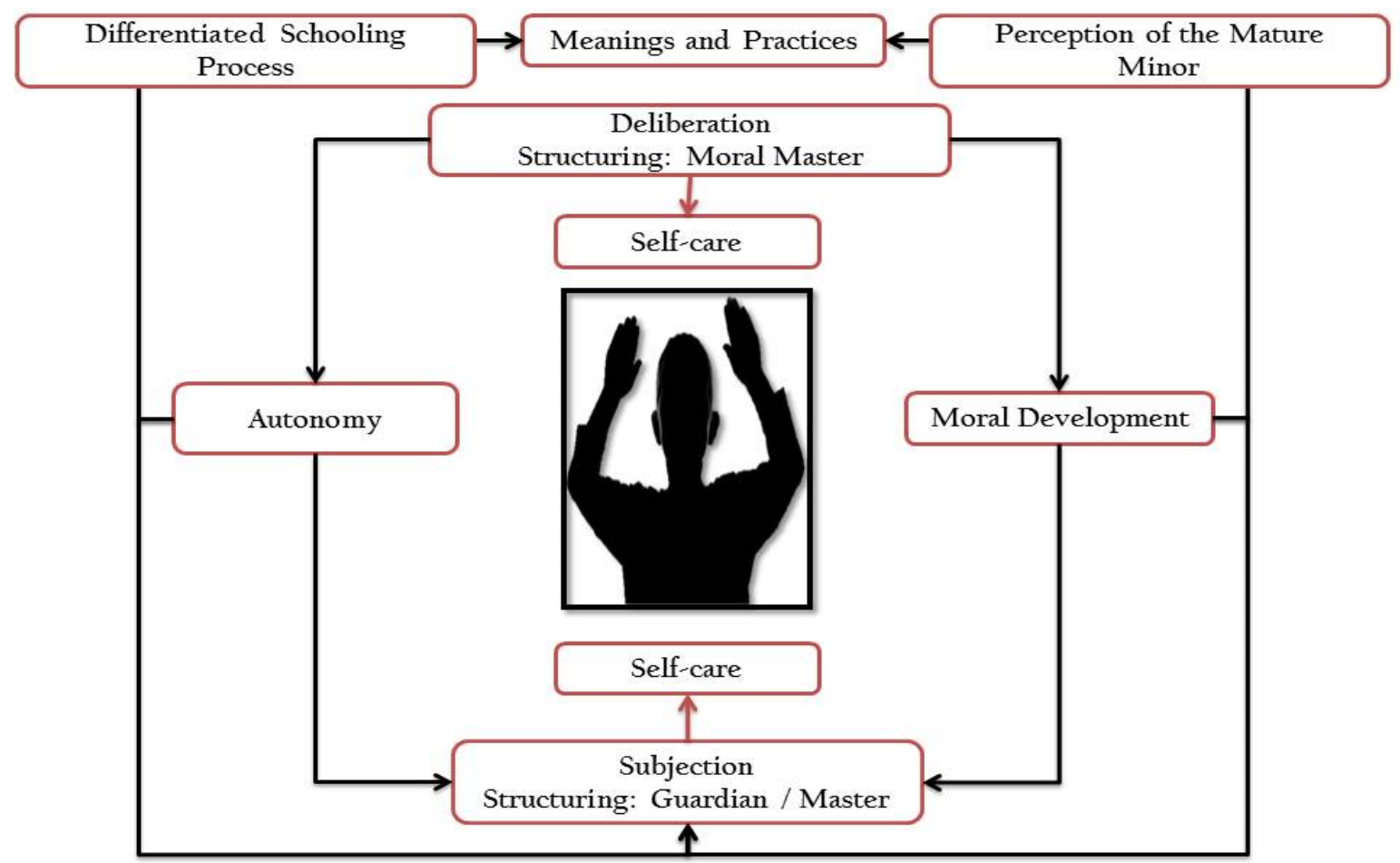

Figure 1. Differentiated process of objectification [schooling]

It should be noted that, from the perception of the meanings of autonomy that emerge from clinicians or researchers, in order to improve the minor's quality of life, it is necessary to have a good development of common sense, that is defined as the way in which the minor understands the information provided in relation to the sense of utility.

The categories sense of utility, quality of life, minor troubled and common sense were considered as emergent categories, because they were the result of the analysis made to the categories of meanings and moral development, which were constructed and described keeping in mind the following voices:

\subsection{Emergent Category: Common Sense}

Clinicians describe this category as the degree of understanding and comprehension that the minor has, also in relation to their experiences with the disease. When the minor is able to accept the treatment because he recognizes the seriousness of his condition. To illustrate this category better, the following voices are exposed:

Question: Describe how you would inform the minor about the new treatment and what does the level of information that is provided depend on?

- [E-20]-[1:37]: The minor often does not have the ability to discern clearly. But the minor with this type of connective tissue diseases, are children who develop much "common sense", the minor must be made to understand the importance of medicines; The problem lies mainly in the route of administration "injections" and with the periodicity with which are administrated especially that this type of pathology are carried out biological therapies. Most minors when they are explained well end up accepting the treatment for at least one injection per week.

Question: Doctor, from your perception, the maturity that is possibly demonstrated by the minor in matters of self-care could be extrapolated to other areas of his life and in what sense?

- $\quad$ [E-12]-[1:178]: Yes, as long as they understand their current health status.

\subsection{Emergent Category: Sense of Utility}

This category consists in getting the minor to participate actively in the process without restrictions of any kind, informing him about the most convenient options and allowing him to express his points of view and perspective of his situation, as stated in the following voices:

Question: From your assistance or research practice, how do you think it contributes to the strengthening of moral development, understood as the autonomy, freedom and responsibility of the minor for making decision making 
through moral judgments?

- [E-5]-[1:229]: The minor's opinion must be taken into account and given the importance it deserves, listening to their concerns and expectations and what they know about their illness.

- [E-6]-[1:230]: 1. Reporting properly. 2. Allow feedback. 3. Respect and guide their perspective of the situation.

\subsection{Emergent Category: Quality of Life}

The quality of life is related to the way the minor handles the information about his pathology, if he is able to understand the benefits and risks, and if he has a good self-care. The possibility of achieving the quality of life of minors lies according to clinicians, such as the ability of minors to adhere to treatment or participation [assent] in biomedical research in accordance with psychological and family support, so it depends in a large extent to the quality of the information provided to the minor, explaining both the adverse events and the physical limitations to which it is exposed if he does not adhere to the treatment, which could even lead to death. According to the perception of the clinicians, this depends to a large extent on the reasoning and logic of the minor at the moment of assent, as explained below:

Question: What errors would you consider that there were and what strategy would you implement for the minor to accept?

- [E-8]-[1:59]: I am carrying out a study that will probably improve your quality of life, it is a medicine with beneficial effects in terms of your functional recovery of your joints, but you can present adverse events expected. Would you like to participate?

Question: What elements do you consider important at the time to consider that the minor can or can not make a decision regarding a new treatment?

- [E-2]-[1:93]: That he understands his illness in relation to the complications and its repercussion to his quality of life, but above all that he understands that he can die at an early age.

Question: According to your experience, what would depend on the minor being able to make an important decision regarding his health, specifically his self-care?

- [E-4]-[1:95]: It improves the quality of life and its relationships with family and social environment.

- [E-13]-[1:141]: Of psychological support. Family support. Benefits and quality of life.

- [E-16]-[1:145]: Desire to improve. Quality of life. Use of information tools.

- [E-17]-[1:146]: If is able to understand about the benefits and improve his quality of life.

Question: In your experience, at what time can the minor be considered a mature subject?

- [E-11]-[1:241]: Since he demonstrates logic and reason in his choices regarding to his wellbeing

\subsection{Emergent Category: Conflictive Minor}

The category of the conflictive minor is indisputably an emerging concept in the training process performed by the clinician, since it is also present as one of the elements that defines the practices of clinicians within the doctorpatient relationship of extreme paternalism type, because some clinicians consider that it is due to the lack of moral development of the minor to understand the information [immaturity]. On the other hand, other clinicians consider that it is due to the lack of a clear language and adjusted to the moral development of the child. It should also be mentioned that the fears of the minor regarding treatment, especially the administration route [injections], also influence the negativity or conflict that may arise at the time of the informed assent process, as the following voices show:

Question: What errors would you consider that there were and what strategy would you implement for the minor to accept?

- [E-19]-[1:80]: I think that there are no errors, but that the information provided is broad, true and comparable with the level of scientific evidence to demonstrate the benefits of the treatment.

- $\quad$ [E-20]-[1:81]:. It exposes a case of a patient who did not want to be examined. Especially the boys who are in adolescence between 14, 15 and 16, who are in the stage of adolescence, which are a little reluctant, but with a good explanation and the intervention of the parents end up accepting. Communicate always to the patient the truth in relation to the benefits and adverse effects, since as the adolescent he realizes that it is a lie, the management would be worse. 
Question: Describe how you would inform the minor about the new treatment and what does the level of information that is provided depend on?

- [E-20]-[1:46]: [...] The problem lies mostly in the route of administration "injections" and the frequency with which it is placed, especially that this type of pathology biological therapies are carried out [...].

\section{Discussion and Conclusions}

The research and care practices in the field of pediatrics invites us to consider how the moral development of the child can be contributed through elements such as those proposed in this research from external and internal factors, which contribute to the formulation of strategies to strengthen the moral development of the child from the patient doctor relationship, which has been called the differentiated process of objectification [schooling] which is corroborated by (Barra Almagia, 1987, Hersh, Reimer and Paolitto, 1984). Understanding that he vulnerability of the minor must not justify the violation of his right to agree. On the contrary, it is a moral duty to contribute to its development, since according to Herder, the human being comes into the world "weak [...], needy [...], abandoned of the teachings of nature [...], and lacking in skills and talents" (As cited in Kottow, 2012, page 27). However, "man is no more than a cane, the most fragile of nature, but it is a thinking cane" (Pascal \& Blaise, 1986).

The findings of this research allow us to highlight the importance of the proposal presented as a differentiated process of objectification [schooling], which identifies the importance of analyzing the meanings of autonomy and moral development that clinicians have with respect to the minor with autoimmune disease, to propose mechanisms of communication and moral schooling of the minor, which emerge from doctor-patient relationships as the most convenient according to the results of the deliberative and paternalistic model.

With regard to considering a minor as mature or autonomous, clinicians say that this depends a lot on their level of understanding of the disease and how it is reflected in self-care practices, in addition to the degree of dependence of the child with their parents. In a few words, and according to what was stated by (Labouvie-Vief, Grühn, \& Studer, 2010), there is a relationship between consent and parental authorization, where each one has a different objective. For example, supervision of the guardian is intended to protect the child from taking unreasonable risks but also to strengthen their autonomy when demonstrating fair and responsible decisions regarding their health. On the other hand, assent is a communication process that seeks to strengthen the sense of usefulness and achieve the minor to adhere to the treatment for life. Even 9-year-olds have demonstrated the ability to make reasonable choices, as long as they are explained with adequate language (Hurley \& Underwood, 2002; Burke et al., 2005).

Clinicians can perceive autonomy and moral development as dependent and interrelated elements, since they can consider the minor as a subject with the capacity to determine the consequences of their actions according to the pathology and with elements of their age. However, for (Benston, 2016), clinicians must meet other criteria, for example, the legal aspects that determine that a minor can make decisions (after 18 years in Colombia), independence with respect to their parents or the degree of emancipation, the sociocultural aspects that surround it, the capacity of listening and deliberation which ultimately determine its acceptance, but above all its adherence to treatment, that is, it must not be associated with a conflictive or immature minor.

In summary, the informed consent is a process of assertive communication ethical model that seeks the moral structuring of the minor beyond what is perceived by the clinician or researcher. It was found that informed consent is a bridge or convergent point between the meanings of autonomy and the power practices of clinicians and researchers, since it was considered in both models of doctor-patient relationship as a primary method to achieve in the child the sense of utility or, as (Djaballah, 2008) highlights, the dialectical submission as an instrument of power to achieve the structuring of the minor. In addition, it should be mentioned that clinicians and researchers believe that the minor's experience with the disease contributes to their self-determination and therefore, to better understand their responsibility in self-care; as long as it is proven that the disease has not affected their Cognitive ability.

Clinicians and researchers in general do not think that the minor's age can be something that avoids a good process of taking informed consent. However, they consider necessary the participation of the parents or legal guardian when informing the minor about the importance of their self-care and about the risks and benefits of medical treatment in order to avoid legal problems. It is clear that the meanings of autonomy and moral development of clinicians are manifested in practices that seek the well-being of the minor, which depends in a great extent on their adherence to treatment, which requires both models of parental intervention as a way to strengthen the child's support outside of the clinic or the study.

\section{Competing Interests Statement}

The authors declare that there are no competing or potential conflicts of interest. 


\section{References}

Bardin, L. (1991). Análisis de contenido (Vol. 89). Madrid: Ediciones Akal.

Barra Almagia, E. (1987). El desarrollo moral: una introducción a la teoría de Kohlberg. Revista Latinoamericana de psicología, 19(1), 7-18.

Benston, S. (2016). Not of Minor Consequence: Medical Decision-Making Autonomy and the Mature Minor Doctrine. Ind. Health L. Rev., 13(1), 1-16. https://doi.org/10.18060/3911.0011

Burke, T. M., Abramovitch, R., \& Zlotkin, S. (2005). Children's understanding of the risks and benefits associated with research. Journal of Medical Ethics, 31(12), 715-720. https://doi.org/10.1136/jme.2003.003228

Djaballah, M. (2008). Kant, Foucault, and forms of experience. Nueva York: Routledge. https://doi.org/10.4324/9780203929087

Goodwin, M., \& Duke, N. (2011). Capacity and autonomy: a thought experiment on minors' access to assisted reproductive technology. Harvard Journal of Law \& Gender, 34, 504-552.

Guillén, D. G. (1997). Bioética y pediatría. Rev Esp Pediatr, 53(2), 99-106.

Hersh, R. H., Reimer, J., \& Paolitto, D. P. (1984). El crecimiento moral: de Piaget a Kohlberg (Vol. 34). Madrid: Narcea Ediciones.

Hurley, J. C., \& Underwood, M. K. (2002). Children's understanding of their research rights before and after debriefing: Informed assent, confidentiality, and stopping participation. Child Development, 73(1), 132-143. https://doi.org/10.1111/1467-8624.00396

Kottow, M. (2012). Vulnerabilidad entre derechos humanos y bioética. Relaciones tormentosas, conflictos insolutos. Derecho PUCP, (69), 25-44.

Labouvie-Vief, G., Grühn, D. Y Studer, J. (2010). Dynamic integration of emotion and cognition: Equilibrium regulation in development and aging. The handbook of life-span development, (2), 79-115. https://doi.org/10.1002/9780470880166.hlsd002004

Lyon, R.-M. (1987). Speaking for a Child: The Role of Independent Counsel for Minors. Cal. L. Rev., 75(2), 681706. https://doi.org/10.2307/3480627

MonatschriFT, B. (1984). Michel Foucault. What is Enlightenment? New York: Pantheon.

Oliva, F. (2014). El menor maduro ante el derecho. Eidon, (41), 28-52.

Packer, M. (2013). La ciencia de la investigación cualitativa. Bogotá: Ediciones Uniandes (Universidad de los Andes). https://doi.org/10.7440/2013.48

Pascal, B. (1986). Pensamientos. Madrid, Alianza

Sánchez Vázquez, M. J. (2007). Ética e infancia: el ni-o como sujeto moral, Fundamentos en Humanidades. VIII(I), 179/192.

Serrano LópeZ, M. L. (2014). Aspectos éticos de la investigación en salud en ni-os. Revista Colombiana de Bioética, 9(1), 183-196. https://doi.org/10.18270/rcb.v9i1.754

\section{Copyrights}

Copyright for this article is retained by the author(s), with first publication rights granted to the journal.

This is an open-access article distributed under the terms and conditions of the Creative Commons Attribution license (http://creativecommons.org/licenses/by/4.0/). 